\title{
Serotonin- and training-induced dynamic regulation of CREB2 in Aplysia
}

\author{
Rong-Yu Liu, ${ }^{1}$ Shreyansh Shah, ${ }^{1}$ Leonard J. Cleary, and John H. Byrne ${ }^{2}$ \\ Department of Neurobiology and Anatomy, W.M. Keck Center for the Neurobiology of Learning and Memory, The University of Texas \\ Medical School at Houston, Texas 77030, USA
}

\begin{abstract}
Long-term memory and plasticity, including long-term synaptic facilitation (LTF) of the Aplysia sensorimotor synapse, depend on the activation of transcription factors that regulate genes necessary for synaptic plasticity. In the present study we found that treatment with 5-HT and behavioral training produce biphasic changes in the expression of CREB2, a transcriptional repressor. An immediate increase in CREB2 protein was followed by a subsequent decrease. The effects of these treatments persist for at least $24 \mathrm{~h}$ and are observed in isolated sensory neurons. This study suggests that the dynamics of CREB2 expression could contribute to the consolidation of memory.
\end{abstract}

Long-term memory and plasticity, including sensitizationinduced long-term synaptic facilitation (LTF) of the Aplysia sensorimotor synapse, depend on the activation of transcription factors that regulate genes necessary for synaptic plasticity. Application of 5-HT, a neurotransmitter that mimics sensitization training, facilitates this synaptic connection (Montarolo et al. 1986; Emptage and Carew 1993; Zhang et al. 1997). Accumulating evidence suggests that the cAMP-response element-binding protein (CREB) family of transcription factors serves a key role in regulating gene expression required for LTF and long-term memory (LTM) (Dash et al. 1990; Bartsch et al. 1998; Liu et al. 2008; Alberini 2009). Protein kinase A (PKA) phosphorylates the transcriptional activator CREB1 and activates CRE-dependent gene expression necessary for the induction of LTF (Bartsch et al. 1995, 1998; Dash and Moore 1996; De Cesare et al. 2000; Lee et al. 2003; Alberini 2009). Another transcription factor important for the induction of LTF is the transcriptional repressor CREB2. 5-HT leads to relief of CREB2-mediated repression (Bartsch et al. 1995). This derepression appears to be due to activation of extracellular signal-regulated kinase (ERK), which, like PKA, is required for LTF (Martin et al. 1997; Sharma et al. 2003; Sharma and Carew 2004) and for long-term sensitization (LTS) (Sharma et al. 2003). The combined activation of CREB1 and removal of CREB2mediated repression leads to the induction of genes essential for LTF (Kandel 2001).

creb1 expression is itself activated by 5-HT and elevated levels are observed up to $24 \mathrm{~h}$ after treatment (Bartsch et al. 1998; Mohamed et al. 2005; Liu et al. 2008). CREB1 binds to the promoter of its own gene, suggesting that positive feedback, mediated by activated CREB1, contributes to the sustained activation of this gene (Mohamed et al. 2005). Moreover, blocking this putative feedback by injection of CREB1 antibody into the presynaptic sensory neurons after 5-HT treatment blocked LTF (Liu et al. 2008). Therefore, it appears that a persistent increase in CREB1 levels, sustained by the positive-feedback loop, helps to maintain gene activation essential for the consolidation of LTF. The observation that levels of CREB1 are dynamically regulated suggests

\footnotetext{
1These authors contributed equally to this work.

${ }^{2}$ Corresponding author.

E-mail john.h.byrne@uth.tmc.edu; fax (713) 500-0623.

Article is online at http://www.learnmem.org/cgi/doi/10.1101//m.2112111.
}

that CREB2 may be regulated as well. Indeed, the creb2 promoter region has a single variant CRE (Mohamed et al. 2005). However, an initial investigation failed to find regulation of CREB2 mRNA in ganglia up to $5 \mathrm{~h}$ after treatment with 5-HT (Mohamed et al. 2005). Because we found long-term regulation of both CREB1 proteins (Liu et al. 2008) and because CREB2 is regulated in other model systems (Costa-Mattioli et al. 2005, 2007), we examined CREB2 transcription at later times by directly measuring the effects of 5-HT on expression of CREB2 protein. We also examined whether behavioral training leads to changes in the levels of CREB2 protein.

One-day sensitization training was performed as described previously (Wainwright et al. 2002). Briefly, a train of 10 strong AC electric shocks (60-mA maximal intensity, 500-msec pulses, $1 \mathrm{~Hz}$ ) was applied diffusely to the lateral body wall of one randomly chosen side of the animal via a hand-held electrode. The training protocol consisted of a block of four trains of 10 shocks with 30-min intervals between trains and a total training time of $90 \mathrm{~min}$. Either immediately, 12, or $24 \mathrm{~h}$ after the end of training, a pair of pleural ganglia from each animal was removed, one ipsilateral and one contralateral (control) to the trained side. Protein from ipsilateral and contralateral ganglia was extracted and processed for Western blot analysis as described below. Western blots were performed in a "blind" manner. Data were presented as medians and interquartile ranges because they did not fit a normal distribution. The Wilcoxon Signed Rank test was used for statistical analysis (SigmaPlot).

For experiments involving serotonin-induced changes in CREB2 mRNA and protein, ganglia were treated with five 5-min pulses of either vehicle (L15:ASW, vehicle treatment) or $50 \mu \mathrm{M}$ 5-HT with an interpulse interval of $20 \mathrm{~min}$ (5-HT treatment). Either immediately or at the indicated times after treatment ganglia were rinsed with L15:ASW, rapidly frozen on dry ice, and stored at $-80^{\circ} \mathrm{C}$ until further processing. The composition of ASW and modified L15 has been published elsewhere (Zhang et al. 1997; Antzoulatos et al. 2003). For each measurement of mRNA, two naïve animals were anesthetized by injection of isotonic $\mathrm{MgCl}_{2}(0.5 \mathrm{~mL} / \mathrm{g})$ and the two bilaterally symmetric pairs of pleural-pedal ganglia were surgically isolated. To obtain sufficient RNA for qPCR, the pleural ganglion from the right side of one animal was pooled with the left ganglion from a second animal. For Western blot analysis one pair of pleural-pedal ganglia 
was used for each measurement. The left or right ganglia were randomly assigned to receive the treatment, whereas the contralateral side served as control.

For qPCR analysis of CREB2 mRNA, Aplysia pleural ganglia were given vehicle or 5-HT treatment. Total RNA was isolated from frozen pleural ganglia using Trizol (Invitrogen) and treated with RNase-free DNAse I to remove any contaminating genomic DNA. One-hundred nanograms of total RNA were loaded into each well. Average Ct values were about 20 cycles. $18 \mathrm{~S}$ rRNA was used to normalize the data for loading. Quantification of mRNA was done as described previously (Mohamed et al. 2005).

For Western blots, pleural-pedal ganglia were treated with vehicle or 5-HT and were lysed at various time points after the end of treatment as described previously (Liu et al. 2008). The membrane was probed with anti-ApCREB2 (1:500), followed by incubation with peroxidase-conjugated secondary antibody (1:2,000; Zymed). Immunoreactive bands were visualized by ECL (GE Healthcare) and analyzed with ImageQuant 5.0 software. The anti-CREB2 antibody was raised by a commercial vendor (Genemed Synthesis, Inc.) against the unphosphorylated version of a CREB2 hybrid peptide (SPPDSPEQGPSSPET) constructed to juxtapose the sequences immediately surrounding two putative MAPK phosphorylation sites (Mohamed et al. 2005). Binding specificity was characterized in the earlier study (Mohamed et al. 2005). The same membrane was stripped and reprobed with antiglyceraldehyde 3-phosphate dehydrogenase (GAPDH, 1:2000; IMGENEX) to provide a loading control. Immunoreactive bands were visualized by ECL and analyzed with ImageQuant 5.0 software. The immunoreactivity for CREB2 was normalized to that for GAPDH. Data was analyzed with a paired $t$-test (SigmaPlot).

Immunofluorescence analysis was performed on Aplysia sensory neuron cultures as described previously (Schacher and Proshansky 1983; Chin et al. 2002; Liu et al. 2008). Cultures were given vehicle or 5-HT treatment. At various time points after the end of treatment, cells were fixed and incubated overnight at $4{ }^{\circ} \mathrm{C}$ with anti-ApCREB2 antibody $(1: 250)$. Secondary antibody (goat anti-rabbit secondary antibody conjugated to Cy-3 [Jackson ImmunoResearch Labs]; 1:200 dilution) was applied for $1 \mathrm{~h}$ at room temperature. Images were obtained with a Zeiss LSM 510 confocal microscope using a $63 x$ oil-immersion lens. A zseries of optical sections through the cell body $(0.5-\mu \mathrm{m}$ increments) was taken, and the section through the middle of the nucleus was used for analysis of mean fluorescence intensity with Metamorph Offline software (Universal Imaging Corporation). Immunoreactivity to CREB2 antibody was observed in both cytoplasm and nucleus in cultured SNs. The immunostaining intensity in both compartments was analyzed separately. All neurons on each coverslip (5-10) were imaged, and measurements from neurons on the same coverslip were averaged. Data were analyzed with paired $t$-test (SigmaPlot). Immunofluorescence analysis was performed in a "blind" manner.

We found that CREB2 mRNA and protein levels are dynamically regulated in ganglia after treatment with 5-HT. Following treatment with five pulses of either vehicle (time matched controls) or 5-HT, pleural ganglia were collected and frozen either immediately, $1,2,5,12$, or $24 \mathrm{~h}$ after the last treatment pulse. Confirming previous findings (Mohamed et al. 2005), we failed to observe any significant changes in CREB2 mRNA levels at early time points after 5-HT compared with time matched controls (Fig. 1A, mean \% control \pm SEM: immediately: $113.9 \pm 8.2$, $t_{(13)}=1.7, P>0.05 ; 1 \mathrm{~h}: 121.9 \pm 16.3, t_{(13)}=1.2, P>0.05 ; 2 \mathrm{~h}:$ $96.8 \pm 9.2, t_{(13)}=1.1, P>0.05 ; 5 \mathrm{~h}: 113.2 \pm 11.4, t_{(13)}=0.4, P>$ 0.05). However, at $12 \mathrm{~h}$ after 5-HT, we observed a significant decrease in CREB2 mRNA levels $\left(72.6 \pm 5.4, t_{(6)}=4.9, P<0.01\right)$. The decrease appeared to be transient because at $24 \mathrm{~h}$, CREB2

\section{A CREB2 mRNA}

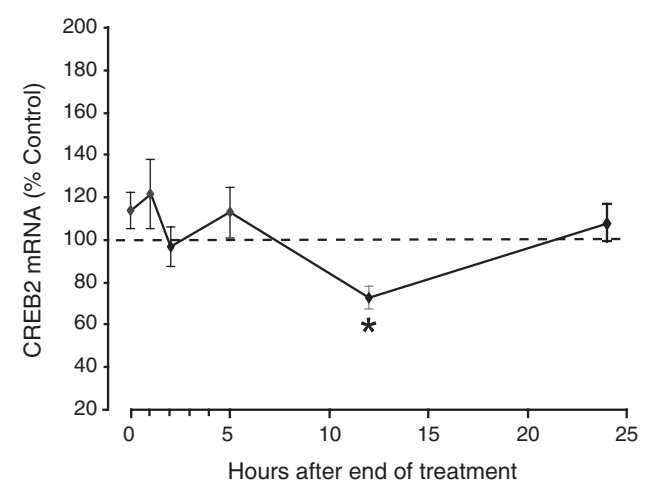

\section{B1 CREB2 protein}
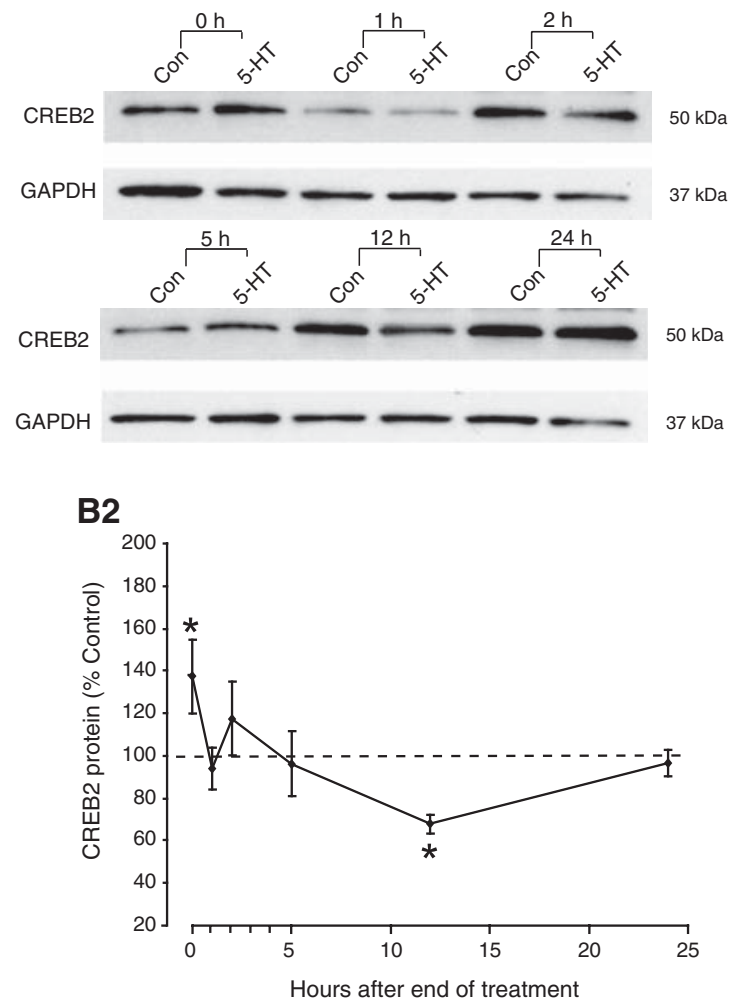

Figure 1. Dynamics of CREB2 $m R N A$ and protein in ganglia after 5-HT treatment. ( $A$ ) Summary data from qPCR representing CREB2 mRNA levels immediately (0), 1, 2, 5, 12, and $24 \mathrm{~h}$ after 5-HT treatment and normalized to vehicle-treated, time-matched controls. CREB2 mRNA levels were unchanged immediately, 1, 2, 5, and $24 \mathrm{~h}$ after 5-HT treatment, but significantly decreased at $12 \mathrm{~h}$ after 5 -HT treatment $\left(\left[{ }^{*}\right] P<0.05\right)$. (B1) Representative Western blots from ganglia treated with vehicle or 5-HT. Membranes were probed with anti-CREB2 and anti-GAPDH antibodies. (B2) Summary data from Western blot analysis representing CREB2 protein levels immediately (0), 1, 2, 5, 12, and $24 \mathrm{~h}$ after 5 -HT treatment and compared with vehicle-treated, time-matched controls. CREB2 protein was normalized to levels of GAPDH, which served as a loading control. CREB2 protein levels were significantly increased immediately following 5-HT treatment, significantly decreased at $12 \mathrm{~h}$, and returned to baseline $24 \mathrm{~h}$ after treatment $\left(\left[{ }^{*}\right] P<0.05\right)$.

mRNA levels were not significantly different from controls $\left(108.0 \pm 9.1, t_{(6)}=1.4, P>0.05\right)$. No significant differences in CREB2 mRNA levels were observed among the vehicle-treated controls (one-way ANOVA, $F_{(5,46)}=0.10, P>0.05$ ). 
A

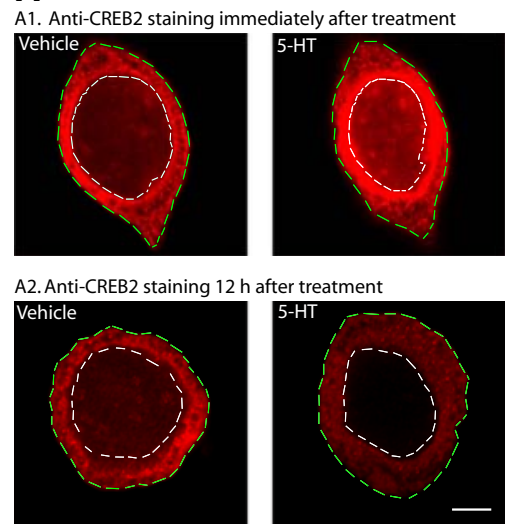

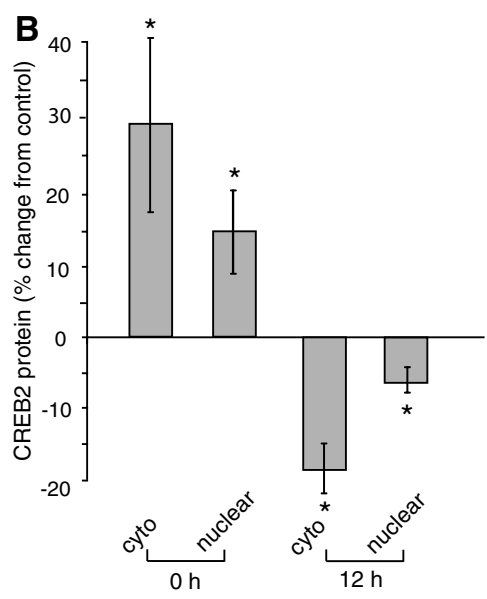

Figure 2. Dynamic regulation of CREB2 in isolated sensory neurons following treatment with 5-HT. (A) CREB2 immunoreactivity in isolated, cultured sensory neurons immediately $(0 \mathrm{~h}, A 1)$ and $12 \mathrm{~h}$ (A2) after treatment with vehicle or 5-HT. The dashed green lines denote the cytoplasmic membrane and the dashed white lines denote the nuclear membrane. Scale bar, $20 \mu \mathrm{m}$. (B) Summary data indicating that treatment with 5-HT significantly increased both cytoplasmic (cyto) and nuclear CREB2 immunoreactivity immediately after $5-\mathrm{HT}$ treatment $\left(\left[{ }^{*}\right] P<0.05\right)$. CREB2 expression in both cytoplasm and nucleus was significantly decreased at $12 \mathrm{~h}$ after treatment $\left(\left[{ }^{*}\right] P<0.05\right)$. For each cell, the immunofluorescence was averaged over the cytoplasmic or nuclear regions. All of the cells from one dish $(\sim 5-10)$ were then averaged together and the dishes treated with 5-HT were compared with the dishes treated with vehicle for each time point.

Western blot analyses of lysates from pleural-pedal ganglia were performed to determine whether the observed changes in mRNA were associated with changes in protein levels (Fig. 1B). Compared with time-matched vehicle controls, CREB2 protein levels from pleural-pedal ganglia were also dynamically regulated by 5 -HT treatment. Interestingly, a significant increase in CREB2 levels was observed immediately after the end of treatment with 5-HT (Fig. 1B2, mean \% control $\pm \mathrm{SEM}, 139.4 \pm 15.6, t_{(4)}=2.6$, $P<0.05)$. This increase was not sustained, however. For a period of at least $4 \mathrm{~h}$, CREB2 levels were unaffected (1 h: $95.4 \pm 8.9$, $t_{(4)}=0.2, P>0.05 ; 2 \mathrm{~h}: 119.2 \pm 15.8, t_{(4)}=1.34, P>0.05 ; 5 \mathrm{~h}:$ $\left.97.7 \pm 13.8, t_{(4)}=0.32, P>0.05\right)$. By $12 \mathrm{~h}$ after 5 -HT treatment, CREB2 levels were significantly reduced $\left(12 \mathrm{~h}: 69.1 \pm 3.8, t_{(4)}=\right.$ 4.30, $P<0.01)$. The decrease appeared to be transient because at $24 \mathrm{~h}$, CREB2 protein levels were not significantly different from controls $\left(98.1 \pm 5.5, t_{(4)}=0.05, P>0.05\right)$. No significant changes in CREB2 protein levels were observed among the vehicle-treated controls (one-way ANOVA, $F_{(5,29)}=0.997, P>0.05$ ). These results indicate that both CREB2 mRNA and protein are dynamically regulated after 5-HT treatment. The time course suggests that regulation of CREB2 protein levels is part of both the early and the late $(12 \mathrm{~h})$ phases of the molecular cascade involved in memory consolidation.

In the experiments described above, CREB2 regulation was examined in whole ganglia, which are comprised of various cell types including interneurons and sensory neurons. To determine whether CREB2 is specifically regulated in sensory neurons, the presynaptic site of plasticity associated with LTF, we cultured sensory neurons and investigated the effect of 5-HT on CREB2 protein at the cellular level using immunofluorescence and confocal microscopy. We focused on two time points, immediately and $12 \mathrm{~h}$ after treatment. Both are times when CREB2 protein levels were significantly affected by 5-HT treatment (Fig. 1). Like the results from ganglia, 5-HT led to biphasic changes in CREB2 levels in isolated sensory neurons. Immediately after 5-HT treatment, total CREB2 protein levels were increased in both cytoplasm and nucleus. Compared with vehicle-treated controls, 5-HT-treated cells showed a $14.9 \pm 6.0 \%$ increase in CREB2 immunofluorescence in the cytoplasm and a $29.0 \pm 12.2 \%$ increase in the nucleus (Fig. 2A1,B, mean \% change from control \pm SEM, cytoplasm staining, $t_{(7)}=3.06, P<0.05$; nuclear staining, $\left.t_{(7)}=2.77, P<0.05\right)$. In contrast, CREB2 levels decreased by $6.2 \pm 1.7 \%$ in the cytoplasm and $18.2 \pm 3.4 \%$ in the nucleus $12 \mathrm{~h}$ after treatment with 5 -HT (Fig. 2A2,B; cytoplasm staining, $t_{(4)}=$ 3.59, $P<0.05$; nuclear staining, $t_{(4)}=$ $4.49, P<0.05)$. These results indicate that the 5-HT-induced changes in CREB2 protein measured in ganglia are recapitulated in SNs.

To confirm the behavioral significance of the findings with 5-HT treatment, we examined whether CREB2 is regulated by behavioral sensitization training of intact animals. Immediately after sensitization training, pleural ganglia, which contain the somata of the sensory neurons, were isolated and CREB2 protein levels were measured using Western blots at either immediately, 12, or $24 \mathrm{~h}$ after training. Because only one side of the animal received sensitizing stimuli, and sensitization is lateralized (Cleary et al. 1998; Wainwright et al. 2002; Antzoulatos et al. 2006; Antzoulatos and Byrne 2007), ganglia from the untrained side of the animal were used as control. CREB2 levels in ganglia from the trained side (ipsilateral) were compared with those in ganglia from the untrained control side (contralateral). Behavioral training produced a dynamic regulation of CREB2 protein levels (Fig. 3). As with 5-HT treatment, CREB2 was increased to $132 \%$ immediately after training (Ipsi vs. Contra, $n=11, P<$ 0.05). Surprisingly, CREB2 levels were also elevated to $140 \%$ at $12 \mathrm{~h}$ after behavioral training $(n=6, P<0.05)$. Consequently, we examined the 24-h time point as well. CREB2 levels were no longer increased and, in fact, were significantly decreased (86.8\%, $n=8, P<0.05)$. Therefore, although the specifics are quantitatively different, both 5-HT and behavioral training led to dynamic regulation of CREB2 protein in a similar biphasic pattern. The differences between the changes produced by behavioral training and those produced by 5 -HT treatment may be due to failure of the 5-HT application protocol to mimic completely the pattern of release of 5-HT produced by in vivo behavioral training.

CREB2 has a strong influence on the induction of long-term synaptic plasticity by competing with CREB1 for regulation of CRE-dependent gene expression (Dash et al. 1990; Bartsch et al. 1998). Injection of anti-ApCREB2 antibodies into sensory neurons caused a single pulse of 5-HT, which normally only induces short-term facilitation lasting minutes, to evoke LTF lasting $>24 \mathrm{~h}$. In addition, overexpression of CREB2 blocked 5-HTinduced LTF (Lee et al. 2003). These results indicate that CREB2, a transcriptional repressor, places inhibitory constraints on LTF (Bartsch et al. 1995; Lee et al. 2003). 5-HT leads to relief of CREB2-mediated repression (Bartsch et al. 1995). The combined activation of CREB1 and removal of CREB2-mediated repression leads to the induction of genes essential for LTF (Kandel 2001). We recently showed that levels of CREB1 are dynamically regulated. A 5-HT treatment protocol that produces LTF led to increased levels of CREB1 mRNA both immediately and up to $24 \mathrm{~h}$ after treatment (Liu et al. 2008). Moreover, this increased message 
A

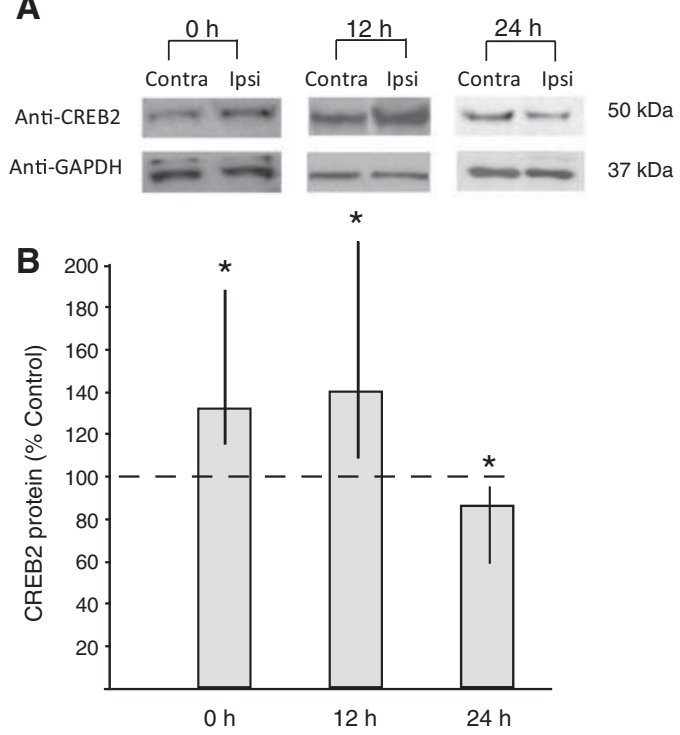

Figure 3. Dynamic regulation of CREB2 in ganglia following behavioral training. $(A)$ Representative Western blots illustrating CREB2 and GAPDH protein levels immediately (0), 12 , or $24 \mathrm{~h}$ after training. Pleural ganglia were removed from both the side contralateral to the trained side of the animal (Contra) and from the ipsilateral side (Ipsi). (B) Summary data indicating that CREB2 protein levels are significantly increased immediately $(0 \mathrm{~h})$ and $12 \mathrm{~h}$ after behavioral training and significantly reduced $24 \mathrm{~h}$ after training. CREB2 protein levels were normalized to GAPDH protein levels for each ganglion. The ratio of ipsilateral to contralateral was used to quantify training-induced changes. Data are presented as medians and interquartile ranges and analyzed with the Wilcoxon Signed Rank test $\left(\left[^{*}\right] P<0.05\right)$.

was associated with increased expression of total and phosphorylated CREB1 protein. LTF was blocked by the injection of antiCREB1 antibody or CREB1siRNA into SNs after 5-HT treatment (Liu et al. 2008, 2009, 2010), indicating that changes in CREB1 expression contribute to the consolidation of LTF.

The present results indicate that CREB2 mRNA and protein are also dynamically regulated, but that the changes have different dynamics. For example, CREB1 levels in ganglia are elevated $12 \mathrm{~h}$ after 5-HT application (Liu et al. 2008), whereas CREB2 levels are reduced (Fig. 1). The functional consequences of the changes in levels of CREB2 and their different dynamics need to be investigated, but it is intriguing to think that they could represent states at which an animal is particularly sensitive to further training. For example, at times when the ratio of CREB1 to CREB2 is increased, another training trial at this time would have a greater probability of activating transcriptional machinery necessary for LTF. Such a "CREB trace" could help explain why multiple learning trials spaced over time are generally more effective in producing long-term memory than single trials or even multiple trials massed together (Cepeda et al. 2006).

The functional consequence of the early increase in CREB2 protein is unclear because it would seem to oppose the induction and consolidation of LTF. However, as in other similar negative feedback motifs found in gene and protein networks (Sneppen et al. 2010; Tyson and Novak 2010), it may serve as a mechanism to constrain a dynamic process. In this case, the consequence would be to help ensure that a single-training trial does not lead to a long-term memory. The early increase in CREB2 protein levels was not associated with a detectable increase in CREB2 mRNA. This dissociation may be due to insensitivity of the qPCR assay. Alternatively, and more intriguing, is the possibility of a post-transcriptional regulation of CREB2 (e.g., Costa-Mattioli et al. 2005, 2007). Irrespective of the mechanism for the increased level of CREB2, the increase does not persist and no significant differences are detected at $1 \mathrm{~h}$ after the end of treatment. One possible explanation for the decrease is that CREB2 has a very short half-life. This possibility seems unlikely because the half-life of CREB1 is > $24 \mathrm{~h}$ (RY Liu, LJ Cleary, JH Byrne, unpubl.). A more likely possibility is that 5-HT leads to an enhanced degradation of CREB2 similar to the 5-HT-induced degradation of the regulatory subunit of PKA mediated by ubiquitin (Hegde et al. 1993), degradation of CCAAT/enhancer binding protein (C/EBP) (Yamamoto et al. 1999), and degradation of the transcriptional repressor CREB1b (Upadhya et al. 2004).

\section{Acknowledgments}

We thank E. Kartikaningrum and J. Liu for preparing the cultures, $\mathrm{W}$. Yao for assistance with the treatment procedures, and P. Smolen and Y. Zhang for their comments on the manuscript. This research was supported by NIH grant NS019895.

\section{References}

Alberini CM. 2009. Transcription factors in long-term memory and synaptic plasticity. Physiol Rev 89: 121-145.

Antzoulatos EG, Byrne JH. 2007. Long-term sensitization training produces spike narrowing in Aplysia sensory neurons. J Neurosci 27: $676-683$.

Antzoulatos EG, Cleary LJ, Eskin A, Baxter DA, Byrne JH. 2003. Desensitization of postsynaptic glutamate receptors contributes to high-frequency homosynaptic depression of Aplysia sensorimotor connections. Learn Mem 10: 309-313.

Antzoulatos EG, Wainwright ML, Cleary LJ, Byrne JH. 2006. Long-term sensitization training primes Aplysia for further learning. Learn Mem 13: $422-425$.

Bartsch D, Ghirardi M, Skehel PA, Karl KA, Herder SP, Chen M, Bailey CH, Kandel ER. 1995. Aplysia CREB2 represses long-term facilitation: Relief of repression converts transient facilitation into long-term functional and structural change. Cell 83: 979-992.

Bartsch D, Casadio A, Karl KA, Serodio P, Kandel ER. 1998. CREB1 encodes a nuclear activator, a repressor, and a cytoplasmic modulator that form a regulatory unit critical for long-term facilitation. Cell 95: 211-223.

Cepeda NJ, Pashler H, Wixted JT. 2006. Distributed practice in verbal recall tasks: A review and a quantitative synthesis. Pshychol Bull 132: $354-380$.

Chin J, Angers A, Cleary LJ, Eskin A, Byrne JH. 2002. Transforming growth factor $\beta 1$ alters synapsin distribution and modulates synaptic depression in Aplysia. J Neurosci 22: RC220. doi: 20026363.

Cleary LJ, Lee WL, Byrne JH. 1998. Cellular correlates of long-term sensitization in Aplysia. I Neurosci 18: 5988-5998.

Costa-Mattioli M, Gobert D, Harding H, Herdy B, Azzi M, Bruno M, Bidinostin M, Ben Mamou C, Marcinkiewicz E, Yoshida M, et al. 2005. Translational control of hippocampal synaptic plasticity and memory by the eIF2 $\alpha$ kinase GCN2. Nature 436: 1166-1173.

Costa-Mattioli M, Gobert D, Stern E, Gamache K, Colina R, Cuello C, Sossin W, Kaufman R, Pelletier J, Rosenblum K, et al. 2007. eIF $2 \alpha$ phosphorylation bidirectionally regulates the switch from short- to long-term synaptic plasticity and memory. Cell 129: 195-206.

Dash PK, Moore AN. 1996. Characterization and phosphorylation of CREB-like proteins in Aplysia central nervous system. Brain Res Mol Brain Res 39: 43-51.

Dash PK, Hochner B, Kandel ER. 1990. Injection of the cAMP-responsive element into the nucleus of Aplysia sensory neurons blocks long-term facilitation. Nature 345: 718-721.

De Cesare D, Fimia GM, Sassone-Corsi P. 2000. CREM, a master-switch of the transcriptional cascade in male germ cells. J Endocrinol Invest 23: $592-596$.

Emptage NJ, Carew TJ. 1993. Long-term synaptic facilitation in the absence of short-term facilitation in Aplysia neurons. Science 262: $253-256$.

Hegde AN, Goldberg AL, Schwartz JH. 1993. Regulatory subunits of cAMP-dependent protein kinases are degraded after conjugation to ubiquitin: A molecular mechanism underlying long-term synaptic plasticity. Proc Natl Acad Sci 90: 7436-7440.

Kandel ER. 2001. The molecular biology of memory storage: A dialog between genes and synapses. Biosci Rep 21: 565-611. 
Lee JA, Kim H, Lee YS, Kaang BK. 2003. Overexpression and RNA interference of Ap-cyclic AMP-response element binding protein-2, a repressor of long-term facilitation, in Aplysia kurodai sensory-to-motor synapses. Neurosci Lett 337: 9-12.

Liu RY, Fioravante D, Shah S, Byrne JH. 2008. cAMP response elementbinding protein 1 feedback loop is necessary for consolidation of long-term synaptic facilitation in Aplysia. J Neurosci 28: 1970-1976.

Liu RY, Cleary LJ, Byrne JH. 2009. CREB1 feedback loop is necessary for consolidation of long-term synaptic facilitation as well as for long-term changes in excitability in sensory neurons of Aplysia. Program No. 888.19. 2009 Neuroscience Meeting Planner. Chicago, IL: Society for Neuroscience, 2009. Online.

Liu RY, Cleary LJ, Byrne JH. 2010. Time window for requirement of CREB1 feedback loop in the consolidation of long-term facilitation of the sensorimotor synapse of Aplysia. Program No. 409.15. 2010 Neuroscience Meeting Planner. San Diego, CA: Society for Neuroscience, 2010. Online.

Martin KC, Casadio A, Zhu H, Yaping E, Rose JC, Chen M, Bailey CH, Kandel ER. 1997. Synapse-specific, long-term facilitation of aplysia sensory to motor synapses: A function for local protein synthesis in memory storage. Cell 91: 927-938.

Mohamed HA, Yao W, Fioravante D, Smolen PD, Byrne JH. 2005. cAMP-response elements in Aplysia creb1, creb2, and Ap-uch promoters: Implications for feedback loops modulating long term memory. J Biol Chem 280: 27035-27043.

Montarolo PG, Goelet P, Castellucci VF, Morgan J, Kandel ER, Schacher S. 1986. A critical period for macromolecular synthesis in long-term heterosynaptic facilitation in Aplysia. Science 234: 1249-1254.
Schacher S, Proshansky E. 1983. Neurite regeneration by Aplysia neurons in dissociated cell culture: Modulation by Aplysia hemolymph and the presence of the initial axonal segment. J Neurosci 3: 2403-2413.

Sharma SK, Carew TJ. 2004. The roles of MAPK cascades in synaptic plasticity and memory in Aplysia: Facilitatory effects and inhibitory constraints. Learn Mem 11: 373-378.

Sharma SK, Sherff CM, Shobe J, Bagnall MW, Sutton MA, Carew TJ. 2003. Differential role of mitogen-activated protein kinase in three distinct phases of memory for sensitization in Aplysia. J Neurosci 23: 3899-3907.

Sneppen K, Krishna S, Semsey S. 2010. Simplified models of biological networks. Annu Rev Biophys 39: 43-59.

Tyson JJ, Novak B. 2010. Functional motifs in biochemical reaction networks. Annu Rev Phys Chem 61: 219-240.

Upadhya SC, Smith TK, Hegde AN. 2004. Ubiquitin-proteasome-mediated CREB repressor degradation during induction of long-term facilitation. J Neurochem 91: 210-219.

Wainwright ML, Zhang H, Byrne JH, Cleary LJ. 2002. Localized neuronal outgrowth induced by long-term sensitization training in Aplysia. J Neurosci 22: 4132-4141.

Yamamoto N, Hegde AN, Chain DG, Schwartz JH. 1999. Activation and degradation of the transcription factor C/EBP during long-term facilitation in Aplysia. J Neurochem 73: 2415-2423.

Zhang F, Endo S, Cleary LJ, Eskin A, Byrne JH. 1997. Role of transforming growth factor- $\beta$ in long-term synaptic facilitation in Aplysia. Science 275: $1318-1320$.

Received December 15, 2010; accepted in revised form January 28, 2011. 


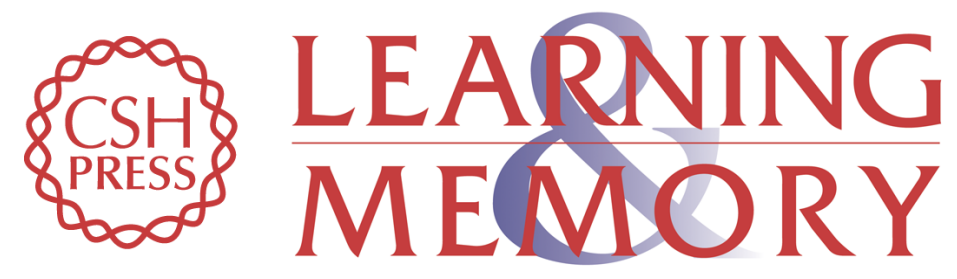

\section{Serotonin- and training-induced dynamic regulation of CREB2 in Aplysia}

Rong-Yu Liu, Shreyansh Shah, Leonard J. Cleary, et al.

Learn. Mem. 2011, 18:

Access the most recent version at doi:10.1101//m.2112111

References

License

Email Alerting Service
This article cites 31 articles, 16 of which can be accessed free at: http://learnmem.cshlp.org/content/18/4/245.full.html\#ref-list-1

Receive free email alerts when new articles cite this article - sign up in the box at the top right corner of the article or click here. 